\title{
Preliminary Outcomes of the Cementless UNITED Hip System for primary Total Hip Arthroplasty at a Minimum Two-year Follow-up
}

Fernando Diaz Dilernia ( $\sim$ fernandodiazdilernia@gmail.com )

Hospital Italiano de Buenos Aires https://orcid.org/0000-0002-7830-2207

Agustin Garcia-Mansilla

Hospital Italiano de Buenos Aires

Agustin Albani-Forneris

Hospital Italiano de Buenos Aires

Pablo Slullitel

Hospital Italiano de Buenos Aires

Gerardo Zanotti

Hospital Italiano de Buenos Aires

Fernando Comba

Hospital Italiano de Buenos Aires

Francisco Piccaluga

Hospital Italiano de Buenos Aires

Martin Buttaro

Hospital Italiano de Buenos Aires

\section{Research article}

Keywords: Total hip arthroplasty, cementless fixation, proximally porous-coated stem, outcomes, survivorship

Posted Date: September 2nd, 2020

DOl: https://doi.org/10.21203/rs.3.rs-68787/v1

License: (c) (i) This work is licensed under a Creative Commons Attribution 4.0 International License.

Read Full License 


\section{Abstract}

\section{Introduction:}

This study aimed to report the initial results of the cementless UNITED hip system in primary total hip arthroplasty (THA) with a minimum follow-up of 2 years.

\section{Methods}

We retrospectively studied a consecutive series of 203 cementless THAs in 180 patients operated between 2015-2017. We included 89 female and 91 male patients with a mean age of 67 (28 to 89) years. The mean follow-up was 40 (29 to 62 ) months. Clinical outcome scores and radiographs were measured. Survival was calculated defining failure as the need for any further femoral or acetabular revision, irrespective of the reason.

\section{Results}

No femoral component loosening was detected. One patient had a Vancouver-B1 intraoperative periprosthetic femoral fracture treated with implant retention and cerclage wires. Two acetabular components were revised for aseptic loosening. Three patients suffered an acute infection treated with debridement, antibiotics, and implant retention. The mean Merle d'Aubigné et Postel scores improved from 13 (4 to 16$)$ points preoperatively to 17 (12 to 18$)$ points at the latest follow-up ( $p<0.001)$. At a mean time of 40 months of follow-up, the survival was $99 \%$ and $100 \%$ for the acetabular and the femoral components, respectively.

\section{Conclusion}

This cementless design showed excellent preliminary outcomes in terms of fixation and patient satisfaction, comparable to that of other well-known similar systems.

\section{Introduction}

The survivorship free of aseptic loosening of any total hip arthroplasty (THA) system depends on many factors, including implant design, fixation technique, and patient demographic characteristics. A recent meta-analysis showed that surgeons can expect survival of $58 \%-78 \%$ at 25 years of follow-up following primary THA [1]. However, it remains a challenge to anticipate if new designs will be able to meet expectations. Therefore, any newly introduced THA design should have its performance subjected to periodical critical review in order to compare its outcome with that of benchmark designs. In order to improve survivorship rates and clinical outcomes of cemented stems, numerous uncemented designs have been developed and remain in use today. 
Different methods have been developed to categorize newly introduced implants and predict their potential failure rate in the long-term. For instance, the Orthopaedic Data Evaluation Panel (ODEP) [2] rates THA implants used in the United Kingdom, based on length of follow-up and quality of evidence.

The uncemented CLS Spotorno (Zimmer, Warsaw, IN, USA) [3], the Taperloc (Zimmer Biomet, Warsaw, IN, USA) [4], the Alloclassic Zweymüller (AlloPro/Sulzer Medica, Winterthur, Switzerland and Centerpulse, Winterthur, Switzerland) [5], and the fully hydroxyapatite (HA) coated tapered Corail (DePuy Synthes, Warsaw, IN) [6] stems have been in use for an extended period and therefore have high ratings with this classification (13A) [2]. The UTFF ${ }^{\mathrm{TM}}$ stem and the U-MOTION II $^{\mathrm{TM}}$ cup (United Orthopaedic Corporation, Taiwan), which were firstly used in 2013 , are still labelled as 'Pre-entry.' In this sense, despite being commercially available, we believe that these hip implants can benefit from further survival analyses.

To our knowledge, there are no clinical or biomechanical reports available evaluating the outcomes of this system in the current literature. Therefore, this study aimed to analyse the initial functional and radiographic outcomes of the UNITED hip system at a minimum 2-year follow-up.

\section{Methods}

This study was performed following the 1964 Declaration of Helsinki principles and was approved by the institution's Research Ethics Board. Informed consent to participate was obtained from all participants and consent to publish was obtained for the patients whose $\mathrm{x}$-rays appear in this manuscript.

We retrospectively studied a consecutive series of 1172 primary THAs operated between 2015 and 2017, of which 528 were hybrid, and 644 were cementless. Of the uncemented femoral components, 225 were fully porous-coated, 112 were short stems, and 307 proximally coated. Of this final group design, 211 were performed using the UNITED hip system (Fig. 1). The use of the UNITED hip system began in February 2015 as part of an institutional contract with the manufacturer, taking into account orthopaedic implant expenditures in our country and a national trend towards cost-savings in orthopaedic care. Neither of the involved surgeons were part of the implant design or have any relevant affiliations with the company. We included all consecutive symptomatic cases older than 18 years, according to the patient's affiliation with the institutional medical insurance. We excluded two cases with inadequate radiographs, one patient who died for non-related causes at 18 months of follow-up, and five cases that were lost to follow-up, leaving a total of 203 uncemented THAs in 180 patients to analyse. Twenty-three patients had bilateral THAs, of which 16 were performed as one-stage bilateral surgeries.

All surgeries were performed in laminar flow operating rooms by one of four fellowship-trained arthroplasty surgeons. Under epidural hypotensive anaesthesia, a posterolateral approach was performed in all patients. Three cases were previously operated with an intramedullary femoral nail (TFN, DePuySynthes, USA) due to an intertrochanteric hip fracture and later developed non-union. All patients received prophylactic antibiotics with three doses of intravenous cefazolin $(1 \mathrm{~g} / 8 \mathrm{hr})$. Routine prophylaxis for thromboembolic disease was indicated during the first postoperative month, consisting of $40 \mathrm{mg}$ subcutaneous low-molecular-weight heparin/day in patients with high clinical risk of thromboembolic 
disease and $325 \mathrm{mg}$ aspirin/day per oral in patients with low clinical risk [7]. The rehabilitation protocol included early mobilization after surgery and ambulation with a walker and full weight-bearing for 15 days. After that, we encouraged patients to progressively return to normal daily activities as tolerated with the use of a cane for at least one month, depending on their clinical evolution and findings on follow-up radiographs. All the data were retrieved from the institution's prospectively collected electronic database. The American Society of Anaesthesiologists (ASA) classification system was used to categorize the patient's physiological status before surgery [8], and Dorr classification [9] was used to classify the proximal femoral morphology. The demographic characteristics of the series are shown in Table 1.

Table 1

Demographic Characteristics of the Series

\begin{tabular}{|ll|}
\hline Patients (hips) (n) & $180(203)$ \\
\hline Gender (F/M) (n) (\%) & $(89 / 91)(49 \% / 51 \%)$ \\
\hline Mean age (years) & $67(28$ to 89$)$ \\
\hline Obese patients (BMl > 30) (kg/m2) (n) (\%) & $69 / 180(38 \%)$ \\
\hline ASA classification (n) (\%) & $4(2 \%)$ \\
ASA 1 & $154(76 \%)$ \\
ASA 2 & $42(20.5 \%)$ \\
ASA 3 & $3(1.5 \%)$ \\
ASA 4 & \\
\hline Mean follow-up (months) & $40(29$ to 62$)$ \\
\hline Initial diagnosis (hips) (n) (\%) & $177(87 \%)$ \\
Idiopathic osteoarthritis & $16(8 \%)$ \\
Avascular necrosis & $7(3.5 \%)$ \\
Hip dysplasia & $3(1.5 \%)$ \\
Implant failure & \\
\hline Dorr's classification (n) (\%) & $170(84 \%)$ \\
A & $31(15 \%)$ \\
B & $2(1 \%)$ \\
C & \\
\hline
\end{tabular}

\section{Surgical Technique}


The UTF ${ }^{\mathrm{TM}}$ stem is a non-modular wedge-shaped type $1 \mathrm{implant}$, according to Khanuja classification for uncemented stems [10]. It has a 12/14 neck taper, and it can be used for primary or revision THA. The stem substrate is made of titanium alloy (Ti-6Al-4V) and is proximally coated with plasma spray (ASTM F-1580) to enhance biological fixation. It has grooves and a distal label that enhances both easy implantation and removal. A broach-only technique is performed with bone-cutting rasps. Preoperative templating is recommended, and standard and high offset options are available for all stem sizes. Lateralization of the canal entry is essential to prevent varus alignment and under-sizing. It is recommended to gradually enlarge the broach size until it contacts the medial and lateral cortices, or the template size is achieved, obtaining axial and rotational stability. The prosthesis should be seated until the most proximal portion of the coating surface is in line with the neck resection level. The interference between implant and broach is $0.5 \mathrm{~mm}$ per side.

The U-MOTION II ${ }^{\text {TM }}$ Acetabular System is a modular implant with hemispherical design. It is made of titanium alloy (ASTM F-620) and is available with two coating options: (a) HA with Ti-plasma spray (ASTM F-1185) (HA-cup) or (b) Ti-plasma spray-only (ASTM F-1580) (PS-cup). Both types of implants utilize Ti-plasma spray coating technology to achieve greater surface roughness ( $\mathrm{Ra})(\mathrm{Ra}=70 \mu \mathrm{m})$. The rough surface provides a scratch fit for initial stability with minimal micromotion. Ceramic and highly cross-linked polyethylene liners (standard or $20^{\circ}$ lipped) fit directly into the metallic shell by taper and snap-in locking mechanism, respectively. Appropriate reaming is essential for the cup to be fully seated. If press-fit is desired for primary implant fixation, under-reaming by $1-2 \mathrm{~mm}$ is recommended according to bone quality. In all patients, we used a PS-cup, and the implantation technique consisted of a line-to-line method for both the femoral and acetabular components. Cup stability was assessed with manual testing, and augmentation with screws was done at the surgeon's choice.

\section{Clinical Assessment}

Clinical outcome was assessed with Merle D'Aubigné score (MDA) [11]. All patients were scored before surgery and at the latest follow-up. Pain evaluation was done according to the visual analogue scale (VAS).

\section{Postoperative Radiographic Assessment}

Anteroposterior (AP) and lateral (L) radiographs of the hip were obtained immediately postoperatively, at 15 days, 6 months, 12 months, and annually thereafter. Two independent observers, who were blinded to clinical outcomes, made all radiographic measurements comparing immediate postoperative radiographs with those made at the latest follow-up. A femoral or acetabular radiolucency was defined as any irregular line between the implant and the bony interface, and periprosthetic osteolysis was defined as progressive bone loss larger than $5 \mathrm{~mm}$ using both Gruen [12] and DeLee and Charnley zones, respectively [13]. The subsidence of the femoral stem was determined using the method described by Loudon and Charnley [14], measuring the distance from a selected (but variable) point in the femoral prosthesis to a fixed point in the bone. Loosening was defined as subsidence of more than $5 \mathrm{~mm}$ or 
continuous demarcation around the stem. Stem fixation was assessed using the method of Engh et al. [15]. The Brooker classification was used to determine the extent of heterotopic ossifications, if any [16].

\section{Complication Rate Analysis}

We registered all complications and we divided them according to the time they appeared. We considered a septic failure as any case requiring revision surgery due to a surgical site infection. We defined an aseptic implant failure whenever any revision surgery performed for non-infectious causes.

\section{Statistical Analysis}

Continuous variables were expressed as means and ranges. Categorical variables were reported as frequencies and percentages. Continuous variables were compared using the independent-samples t-test, where data were normally distributed, and the Mann-Whitney $\mathrm{U}$ test otherwise. Categorical variables were compared using chi-squared and Fisher exact tests. Kaplan-Meier survival curves were estimated considering as an endpoint those complications for any cause that required revision surgery. Odds ratios (OR) were reported with their $95 \%$ confidence intervals $(\mathrm{Cl})$. Variables were considered statistically significant at $p<0,05$. All analyses were performed using Stata $13^{\mathrm{TM}}$ statistical software (StataCorp, College Station, TX).

\section{Results}

The most common acetabular component size was 54-mm, whereas the most frequent femoral component size was 6 . Table 2 shows the surgical variables obtained after surgery. 
Table 2

Postoperative Results

\begin{tabular}{|ll|}
\hline Mean in-hospital stay (days) & $\mathbf{3}$ (1 to 26) \\
\hline Mean surgical time (minutes) & $52(20$ to 120) \\
\hline Mean amount of blood loss (millilitres) & $205(105$ to 400$)$ \\
\hline Blood transfusion (n) (\%) & $3^{\star /} / 180(1.5 \%)$ \\
\hline Mean acetabular screws (n) & $2(0$ to 3$)$ \\
\hline Mean femoral head diameter (millimetres) (n) (\%) & $50(25 \%)$ \\
32 & $143(70 \%)$ \\
36 & $10(5 \%)$ \\
40 & $108(53 \%)$ \\
\hline Bearing surfaces (n) (\%) & $78(39 \%)$ \\
Metal-on-polyethylene & $17(8 \%)$ \\
Ceramic-on-polyethylene & \\
Ceramic-on-ceramic & \\
\hline * All of them had one-stage bilateral procedures & \\
\hline
\end{tabular}

\section{Clinical Assessment}

There was a significant improvement in the MDA score when comparing preoperative and postoperative values [13 (4 to 16) vs. 17 (12 to 18), $p<0.001$ ]. Regarding pain evaluation (VAS), the mean preoperative value was 8 ( 2 to 10$)$, and mean postoperative value was 0 ( 0 to 8$)(p<0.001)$.

\section{Postoperative Radiographic Assessment}

Eleven THAs (5.4\%) had a femoral radiolucency $<2 \mathrm{~mm}$ around the stem. Eight of them were located in Gruen zone 7, and the remaining three cases in Gruen zone 1. All radiolucent lines were detected between the third and sixth postoperative month and remained unchanged, without any clinical relevance. No radiolucency was detected around the acetabular components. There was no evidence of periprosthetic osteolysis in either component. Two patients (1\%) showed initial femoral subsidence $<3 \mathrm{~mm}$, without further progression, remaining asymptomatic to the latest follow-up. There were no cases of femoral stem loosening. Still, two cases with initial radiolucency detected around the acetabular component finally evolved to an aseptic loosening and were treated with one-stage revision surgery (Fig. 2) with a multi-porous acetabular component. None of the two revisions required trabecular metal or allografts. All remaining femoral and acetabular components were fixed with signs of bony ingrowth, according to Engh's method. 


\section{Complication Rate Analysis}

We found 14 complications in the series. Within the first postoperative year, we registered 13 early complications. We recorded no dislocations. Tables 3 show the registered complications, divided by periods of three months.

Table 3

Detailed Complications per Period

\begin{tabular}{|c|c|c|}
\hline \multicolumn{3}{|l|}{ Intraoperative } \\
\hline Complication & Series $(n=203)$ & Treatment \\
\hline Vancouver B1 PFF (n) (\%) & $1(0.5 \%)$ & Cerclage wires and protected weight-bearing \\
\hline \multicolumn{3}{|l|}{ First 90-days } \\
\hline Complication & Series $(n=203)$ & Treatment \\
\hline Acute PJI (n) (\%) & $4(2 \%)$ & Oral antibiotics \\
\hline Superficial & $3(1 \%)$ & DAIR \\
\hline \multicolumn{3}{|l|}{ Deep } \\
\hline Vancouver A PFF (n) (\%) & $2(1 \%)$ & Protected weight-bearing \\
\hline Deep vein thrombosis (n) (\%) & $1(0.5 \%)$ & Oral anticoagulants \\
\hline \multicolumn{3}{|l|}{ After 90-days } \\
\hline Complication & Series $(n=205)$ & Treatment \\
\hline $\begin{array}{l}\text { Ilio-psoas impingement (n) (\%) } \\
(36 \mathrm{~m})\end{array}$ & $1(0.5 \%)$ & Arthroscopic release \\
\hline $\begin{array}{l}\text { Aseptic loosening }(n)(\%) \\
\text { Acetabular cups } \\
(6 \text { and } 23 \mathrm{~m})\end{array}$ & $2(1 \%)$ & $\begin{array}{l}\text { one-stage revision surgery } \\
\text { (primary acetabular cup) }\end{array}$ \\
\hline $\begin{array}{l}\text { PFF: Periprosthetic femoral fra } \\
\text { and implant retention; } \mathrm{m} \text { : mont }\end{array}$ & PJI: Periprosth & joint infection; DAIR: Debridement, antibiotics \\
\hline
\end{tabular}

\section{Survivorship Analysis}

At a mean time of 40 months of follow-up, taking revision of any of the components for any reason as the endpoint, the survivorship of the implant was $99 \%$ and $100 \%$ for the acetabular and the femoral components, respectively (Fig. 3).

\section{Discussion}


There is still controversy regarding the optimal type of cementless femoral and acetabular fixation in primary THA. In this retrospective series, we found that the UNITED hip system had excellent clinical and radiographic results, without revisions of the stem and with only two revisions of the acetabular component due to aseptic loosening at a mean follow-up of 40 months.

Although uncemented, proximally porous-coated tapered stems can be a reliable option for routine THA, they are not without complications. Initial implant stability is essential to avoid early aseptic loosening. In 2011, White et al. [17] retrospectively analysed 81 proximally-porous tapered Accolade $\AA$ stems (Stryker Orthopaedics, Mahwah, NJ, USA) for aseptic migration using Ein-Bild-Roentgen-Analysefemoral component analysis (EBRA-FCA). More than $1.5 \mathrm{~mm}$ of subsidence was observed in $36 \%$ of the stems at 2-years of follow-up. The migration pattern may be a consequence of inadequate initial implant stability. In our series, two patients (1\%) showed initial subsidence $<3 \mathrm{~mm}$, without further progression at the latest follow-up. We believe that stem subsidence may not be a major concern with this type of implant design. Of course, further studies with longer follow-up are needed to confirm these preliminary findings.

Trapezoidal wedge-shaped stems are associated with an increased risk of periprosthetic femoral fractures (PFF), being a major concern after cementless THA [18]. We reported 1 case of intraoperative PFF that did not jeopardize stem fixation and was treated with internal fixation. This was probably related to the trapezoidal shape of the implant, which sometimes may not be suitable for all proximal femoral morphologies. In this scenario, more anatomic, rounded stems may be useful to prevent PPFs when compared to single- or double-wedge components [19]. Abdel et al. [20] reported a $7.7 \%$ and $3.5 \%$ risk for postoperative PFF after cementless and cemented THA, respectively, at 20 years of follow-up. PPF may

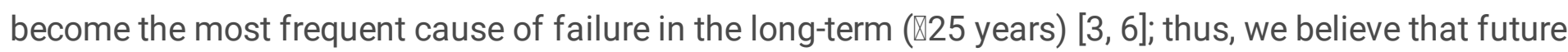
studies with extended follow-up should be performed to analyse this new femoral stem comparing the long-term incidence of PFF, especially among cementless straight implants.

McLaughlin et al. 's previous long-term studies have shown excellent clinical and functional outcomes with the use of a cementless proximally porous-coated tapered collarless titanium stem [4]. Although we are reporting short-term results, our outcomes were comparable to the Taperloc stem in these long-term studies; the mean MDA scores improved from 13 points preoperatively to 17 at the latest follow-up $(p<$ $0.001)$.

Porous titanium-coated (PTC) acetabular cups have not proven to perform better than plasma-sprayed (PS) acetabular shells at medium to long-term follow-up [21]. Lindgren et al. [22] performed a prospective multicentre study comparing PTC and PS cups. The PTC component was associated with a higher risk of pain $(O R=2, p=0.035)$ and radiolucency $(O R=5.2, p<0.001)$; however, there were no cases of revision surgeries for loosening. In our study, we found $2(1 \%)$ acute aseptic loosening of the acetabular component. Both patients were revised with a primary uncemented cup at 6 and 23 months postoperatively. No further complications were registered in these patients, obtaining good clinical outcomes at the latest follow-up. It is essential to mention that both failures were recorded in the first 20 
cases of the series with a PS-cup. We believe that both failures may be related to the learning curve and to the fact that reaming was done line-to-line instead of with a press-fit technique, as it is recommended.

lliopsoas impingement (IPI) after THA is a possible cause of recurrent groin pain and range of motion restriction with a prevalence of $4.4 \%$ [23]. An axial protrusion length $\geq 12 \mathrm{~mm}$, a sagittal protrusion length $\geq 4 \mathrm{~mm}$, a higher native acetabular version, a lower cup anteversion, and inclination have been described as independent predictors of symptomatic IPI [24]. In our series, we had one patient with IPI treated with arthroscopic tendon release. Regarding acetabular cup inclination and anteversion, the patient exhibited normal values for both measures. Although this complication can be seen in sharp acetabular components [25], we recommend assessing the cup-to-rim ratio in order to discard any prominence over the acetabular rim.

Our study was not without limitations. First, its retrospective nature correlated with the biases exclusive to the study design. The sample size of the series resulted in a small number of cases included, restraining the production of more accurate statistical analyses. However, it is the only study investigating the clinical and radiological outcomes of this cementless hip system. Second, our survival rates should be considered as best-case estimates. Because there was a short-term follow-up period, we expect that some of these patients may yet undergo a revision arthroplasty for any reason at a longer follow-up. Third, our data did not include enough comprehensive information about demographics and specific frailtycomorbidities or perioperative factors that would contribute to developing complications. Hence, our complication outcomes should also be considered as best-case estimates. Finally, the gold standard in analysing initial implant stability is radiostereometric analysis [26]. Another reliable option to evaluate implant migration is EBRA-FCA [27], which can also measure stem subsidence without the need for tantalum markers using standard pelvic radiographs. Unfortunately, we were not able to perform this kind of evaluation due to the lack of resources in our centre at the moment this study was developed.

\section{Conclusion}

In summary, this study is the first to describe 203 consecutives UNITED THAs implanted at a nondeveloper, academic teaching hospital. We observed excellent clinical and radiographic outcomes of both the femoral and acetabular components at a mean follow-up of 35 months, with a low complication rate. Therefore, the UNITED hip system appears to have non-inferior outcomes to that of other stem and cup designs. Further studies and extended monitoring of this cohort are required to assess new modes of failure in the long-term.

\section{Abbreviations}

Total hip arthroplasty (THA)

Hydroxyapatite (HA)

The American Society of Anaesthesiologists (ASA) 
Merle D'Aubigné (MDA) score

Visual analogue scale (VAS).

Anteroposterior (AP)

Lateral (L)

Odds ratios (OR)

Confidence intervals (Cl)

Ein-Bild-Roentgen-Analysefemoral component analysis (EBRA-FCA)

Periprosthetic femoral fractures (PFF)

Porous titanium-coated (PTC)

Plasma-sprayed (PS)

lliopsoas impingement (IPI)

\section{Declarations}

\section{Ethics approval and consent to participate}

- Ethics approval

- All procedures performed involving human participants were in accordance with the ethical standards of the institutional research committee and with the 1964 Helsinki Declaration and its later amendments or comparable ethical standards. The study was approved by the institution's Research Ethics Board (November 25 $5^{\text {th }}$ 2019/No. 5179)

\section{- Informed consent}

- Consent to participate: Informed consent was obtained from all individual participants included in the study.

- Consent for publication: Patients signed informed consent regarding publishing their data and images.

\section{Code availability}

- All analyses were performed using Stata $13^{\mathrm{Tm}}$ statistical software (StataCorp, College Station, TX).

\section{Availability of data and materials}

- Not Applicable 


\section{Disclosure of potential competing of interest}

- The authors declare that they have no conflict of interest.

\section{Funding}

- Not applicable/No funding was received.

\section{Authors' contributions}

- All authors contributed to the study conception and design, and read and approved the final manuscript.

- Conceptualization: Martin Buttaro

- Data curation: Fernando Diaz-Dilernia, Agustin Garcia-Mansilla, Agustin Albani-Forneris

- Methodology: Fernando Diaz Dilernia

- Formal analysis and investigation: Fernando Diaz Dilernia, Pablo Slullitel

- Writing - original draft preparation: Fernando Diaz Dilernia, Agustin Garcia-Mansilla, Agustin AlbaniForneris

- Writing - review and editing: Fernando Diaz Dilernia, Pablo Slullitel

- Resources: Gerardo Zanotti, Fernando Comba, Francisco Piccaluga

- Project administration: Gerardo Zanotti, Fernando Comba, Francisco Piccaluga

- Supervision: Martin Buttaro

\section{Acknowledgements}

Not applicable/No funding was received

\section{References}

1. Evans JT, Evans JP, Walker RW, et al. How long does a hip replacement last? A systematic review and meta-analysis of case series and national registry reports with more than 15 years of follow-up. Lancet. 2019;393(10172):647-54. doi:10.1016/S0140-6736(18)31665-9.

2. ODEP product ratings. Orthopaedic Data Evaluation Panel. Available at: URL:http://www.odep.org.uk/; 2017. [Internet].

3. Streit MR, Lehner B, Peitgen DS, et al. What Is the Long-term (27-to 32-year) Survivorship of an Uncemented Tapered Titanium Femoral Component and Survival in Patients Younger Than 50 Years? Clin Orthop Relat Res. 2020;478(6):1283-91. doi:10.1097/CORR.0000000000001203.

4. McLaughlin JR, Lee KR. Total Hip Arthroplasty With an Uncemented Tapered Femoral Component in Patients Younger Than 50 Years of Age: A Minimum 20-Year Follow-Up Study. J Arthroplasty. 2016;31(6):1275-8. doi:10.1016/j.arth.2015.12.026. 
5. Cruz-Pardos A, García-Rey E, García-Cimbrelo E. Total Hip Arthroplasty with Use of the Cementless Zweymüller Alloclassic System: A Concise Follow-up, at a Minimum of 25 Years, of a Previous Report. J Bone Joint Surg Am. 2017;99(22):1927-31. doi:10.2106/JBJS.16.01109.

6. Jacquot L, Bonnin MP, Machenaud A, et al. Clinical and Radiographic Outcomes at 25-30 Years of a Hip Stem Fully Coated With Hydroxylapatite. J Arthroplasty. 2018;33(2):482-90. doi:10.1016/j.arth.2017.09.040.

7. Salvati EA, Sharrock NE, Westrich G, et al. The 2007 ABJS Nicolas Andry Award: three decades of clinical, basic, and applied research on thromboembolic disease after THA: rationale and clinical results of a multimodal prophylaxis protocol. Clin Orthop Relat Res. 2007;459:246-54. doi:10.1097/BLO.0b013e31805b7681.

8. Dripps RD. New classification of physical status. Anesthesiol. 1963;24:111.

9. Dorr LD, Faugere MC, Mackel AM, et al. Structural and cellular assessment of bone quality of proximal femur. Bone. 1993;14(3):231-42. doi:10.1016/8756-3282(93)90146-2.

10. Khanuja HS, Vakil JJ, Goddard MS, Mont MA. Cementless femoral fixation in total hip arthroplasty. J Bone Joint Surg Am. 2011;93(5):500-9. doi:10.2106/JBJS.J.00774.

11. D'Aubigne RM, Postel M. Functional results of hip arthroplasty with acrylic prosthesis. J Bone Joint Surg Am. 1954;36-A(3):451-75.

12. Gruen TA, McNeice GM, Amstutz HC. (1979) Modes of failure" of cemented stem-type femoral components: a radiographic analysis of loosening. Clin Orthop Relat Res, (141):17-27.

13. DeLee JG, Charnley J. (1976) Radiological demarcation of cemented sockets in total hip replacement. Clin Orthop Relat Res, (121):20-32.

14. Loudon JR, Charnley J. Subsidence of the femoral prosthesis in total hip replacement in relation to the design of the stem. J Bone Joint Surg Br. 1980;62-B(4):450-3.

15. Engh CA, Massin P, Suthers KE. (1990) Roentgenographic assessment of the biologic fixation of porous-surfaced femoral components. Clin Orthop Relat Res, (257):107-128.

16. Brooker AF, Bowerman JW, Robinson RA, Riley LH. Ectopic ossification following total hip replacement. Incidence and a method of classification. J Bone Joint Surg Am. 1973;55(8):1629-32.

17. White CA, Carsen S, Rasuli K, et al. High incidence of migration with poor initial fixation of the Accolade stem. Clin Orthop Relat Res. 2012;470(2):410-7. doi:10.1007/s11999-011-2160-z.

18. Boylan MR, Riesgo AM, Paulino CB, et al. Mortality following periprosthetic proximal femoral fractures versus native hip fractures. J Bone Joint Surg Am. 2018;100(7):578-85. doi:10.2106/JBJS.17.00539.

19. Carli AV, Negus JJ, Haddad FS. (2017) Periprosthetic femoral fractures and trying to avoid them: what is the contribution of femoral component design to the increased risk of periprosthetic femoral fracture? Bone Joint J, 99-B(1 Supple A):50-59. doi: 10.1302/0301-620X.99B1.BJJ-2016-0220.R1.

20. Abdel MP, Watts CD, Houdek MT, et al. Epidemiology of periprosthetic fracture of the femur in 32644 primary total hip arthroplasties: a 40-year experience. Bone Joint J. 2016;98-B(4):461-7. 
doi:10.1302/0301-620X.98B4.37201.

21. Reina RJ, Rodriguez JA, Rasquinha VJ, Ranawat CS. Fixation and osteolysis in plasma-sprayed hemispherical cups with hybrid total hip arthroplasty. J Arthroplasty. 2007;22(4):531-4. doi:10.1016/j.arth.2006.11.008.

22. Lindgren V, Galea VP, Nebergall A, et al. Radiographic and Clinical Outcomes of Porous TitaniumCoated and Plasma-Sprayed Acetabular Shells: A Five-Year Prospective Multicenter Study. J Bone Joint Surg Am. 2018;100(19):1673-81. doi:10.2106/JBJS.17.00729.

23. Chalmers BP, Sculco PK, Sierra RJ, et al. Iliopsoas impingement after primary total hip arthroplasty: operative and nonoperative treatment outcomes. J Bone Joint Surg Am. 2017;99(7):557-64. doi:10.2106/JBJS.16.00244.

24. Ueno T, Kabata T, Kajino Y, et al. Risk Factors and Cup Protrusion Thresholds for Symptomatic Iliopsoas Impingement After Total Hip Arthroplasty: A Retrospective Case-Control Study. J Arthroplasty. 2018;33(10):3288-96.e1. doi:10.1016/j.arth.2018.05.017.

25. O'Sullivan M, Tai CC, Richards S, et al. Iliopsoas tendonitis a complication after total hip arthroplasty. J Arthroplasty. 2007;22(2):166-70. doi:10.1016/j.arth.2006.05.034.

26. Schütz U, Decking J, Decking R, Puhl W. Assessment of femoral component migration in total hip arthroplasty: digital measurements compared to RSA. Acta Orthop Belg. 2005;71(1):65-75.

27. Biedermann R, Krismer M, Stöckl B, et al. Accuracy of EBRA-FCA in the measurement of migration of femoral components of total hip replacement. Einzel-Bild-Röntgen-Analyse-femoral component analysis. J Bone Joint Surg Br. 1999;81(2):266-72. doi:10.1302/0301-620x.81b2.8842.

\section{Figures}



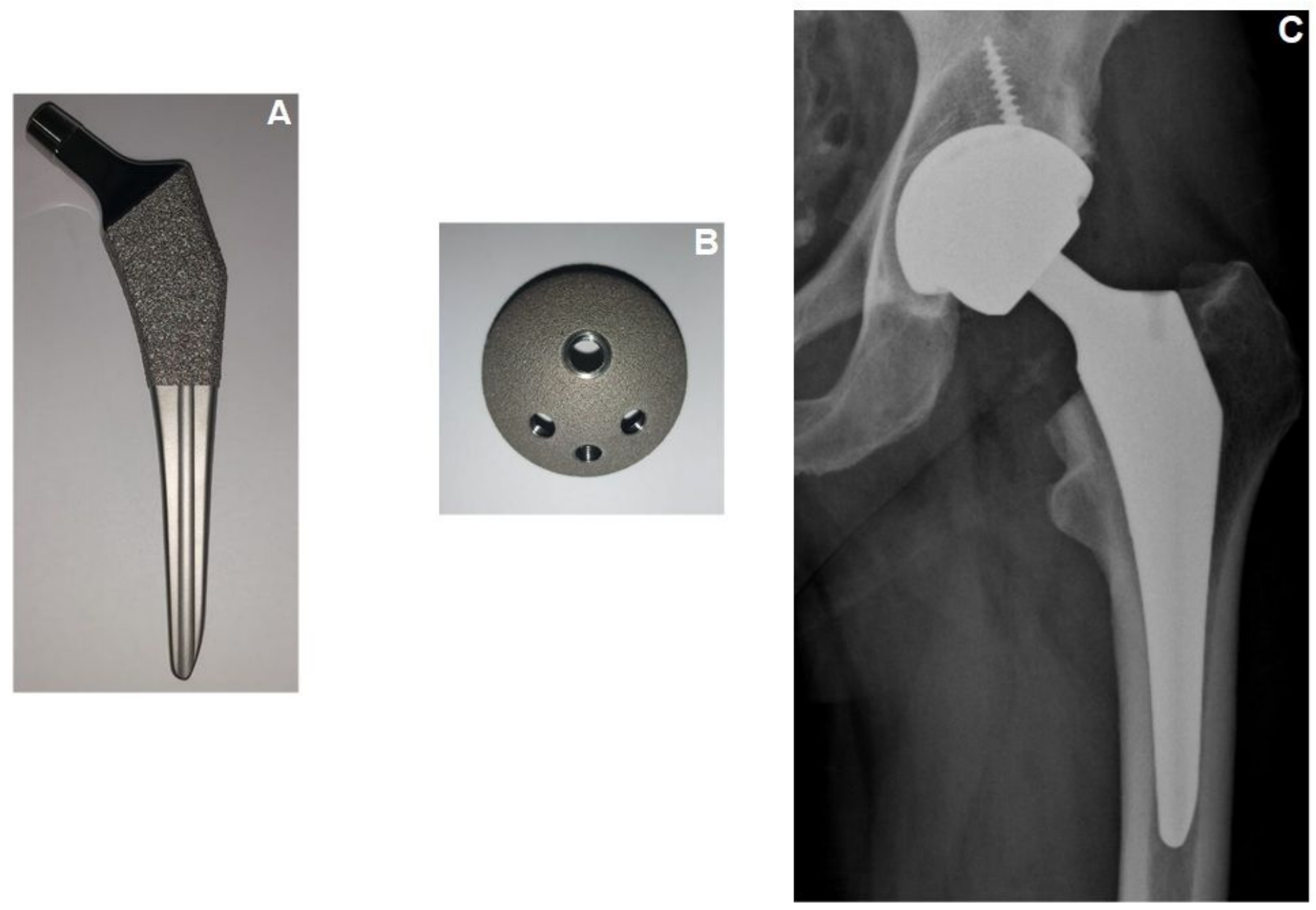

\section{Figure 1}

Photograph of the UTFTM cementless stem (A) and the U-MOTION IITM acetabular cup (B) (United Orthopaedic Corporation, Taiwan). Postoperative AP radiograph showing both components (C)
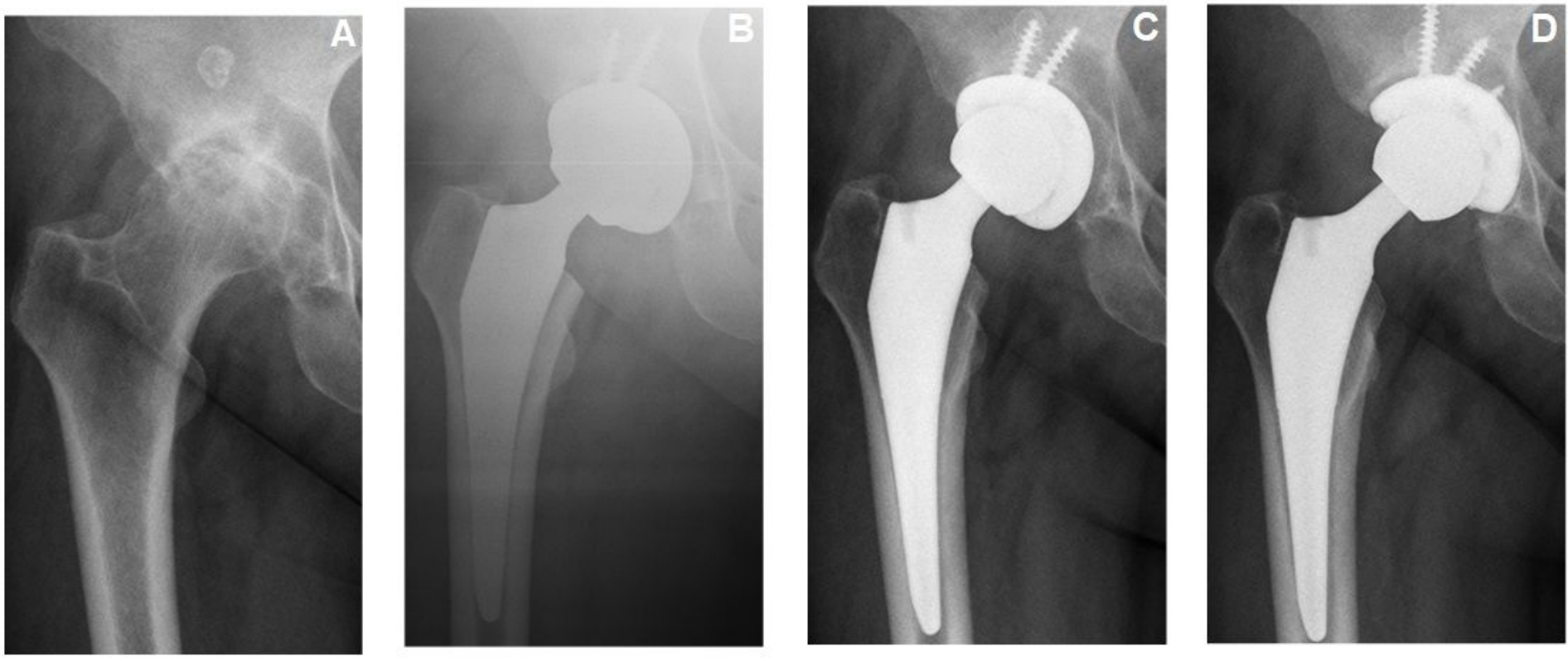

Figure 2 
Serial radiographs of one of the two acetabular aseptic loosening. Preoperative AP radiograph (A). Immediately postoperative AP radiograph showing no evidence of loosening (B). Six months postoperative AP radiograph showing loosening signs located in DeLee and Charnley zone 3 (C). Postoperative AP radiograph (D) after 1-stage revision surgery with a primary acetabular cup, without the need of trabecular metal implant or augments

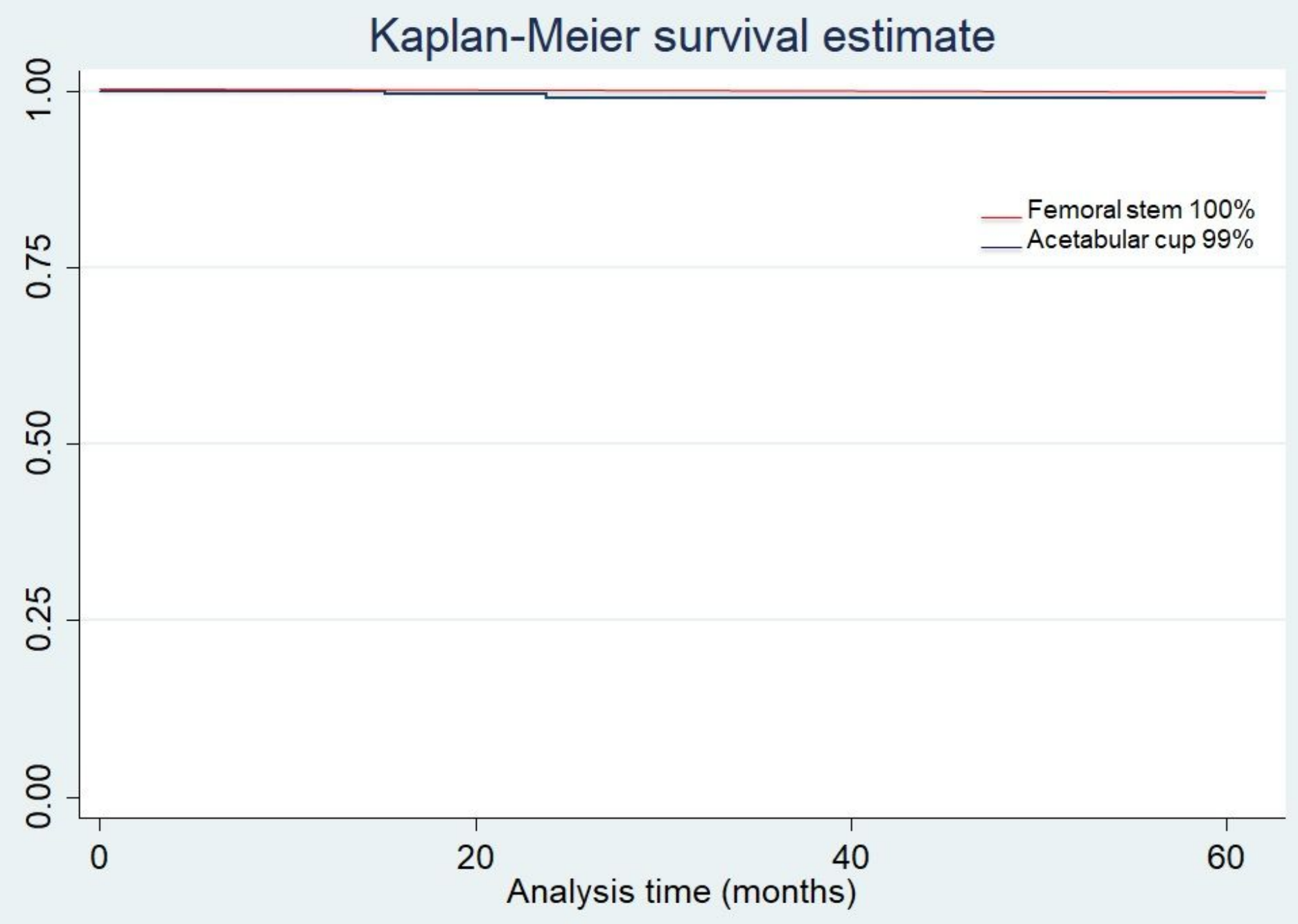

\section{Figure 3}

Kaplan-Meier survival estimates of both acetabular and femoral components. At 35 months of follow-up, the survivorship rate was $99 \%$ and $100 \%$ for the acetabular and the femoral component, respectively 